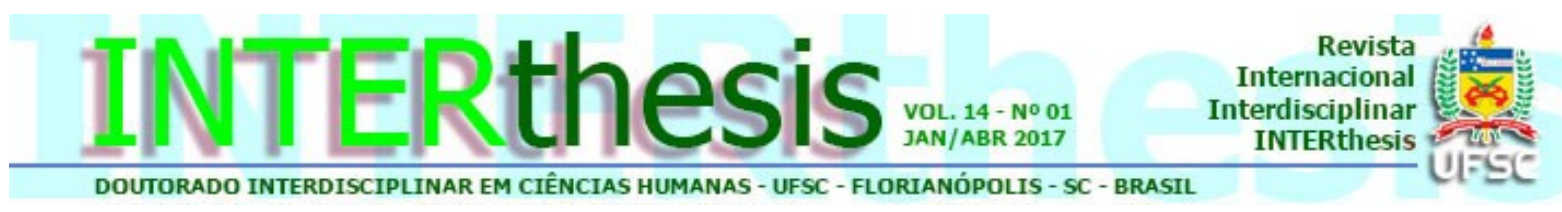

\title{
AS VERDADES EM FOUCAULT E BENJAMIN: UMA CONTRIBUIÇÃO AO CAMPO DA MEMÓRIA SOCIAL
}

Ricardo Salztrager ${ }^{1}$

Felipe Teixeira Lourenço ${ }^{2}$

\section{Resumo:}

A proposta deste artigo é analisar como o conceito de verdade é concebido nos pensamentos de Foucault e Benjamin, destacando a crítica que ambos fazem aos referenciais platônicos. Destacaremos que, em suas teorias, o conceito de verdade deixa de atrelar-se à ideia de essência, passando a adquirir um caráter histórico e contingencial. Ademais, veremos que a verdade é concebida como uma produção e jamais como algo que se encontra escondido desde o princípio e que deve ser devidamente descoberto. Em Foucault, nos centramos nas mais diversas articulações que o conceito de verdade possui com os domínios do poder e do saber. Já de Benjamin, ressaltamos o quanto que o autor valoriza as múltiplas ressignificações que um acontecimento pode sofrer ao longo dos tempos. Portanto, examinamos o quanto Benjamin se distancia da ideia de verdade absoluta, optando por valorizar as mais diversas constelações de verdades e conhecimentos construídos a serem sempre reinterpretados e jamais cristalizados. Por fim, analisamos como nosso estudo pode contribuir para o campo de pesquisas em memória social, na medida em que este pode ser caracterizado como um domínio transdisciplinar que encara o seu objeto de estudo como algo processual.

Palavras-chave: Verdade. Foucault. Benjamin. Filosofia. Memória Social.

\section{INTRODUÇÃO}

A conceituação da verdade é uma das questões fundamentais da filosofia e a busca por seu entendimento a ocupa desde seu nascimento na Grécia Antiga. $\mathrm{Na}$ obra de Platão, por exemplo, a verdade parece estar ligada a "uma teoria do amor e uma teoria da sabedoria: filósofo é o que ama ver a verdade" (ARAÚJO, 2014, p.10). Nestes termos, a verdade consiste em algo a ser buscado por seu amante - o filósofo - e este, como todo amante, busca seu objeto de amor em sua integralidade. Nesta procura por um conhecimento verdadeiro, estabelece-se uma dicotomia entre os amantes da verdade e os amantes da doxa. Para Platão (1997), somente o conhecimento filosófico produz proposições verdadeiras, ao contrário do que se passa no domínio da opinião.

\footnotetext{
${ }^{1}$ Doutor em Teoria Psicanalítica pela Universidade Federal do Rio de Janeiro. Professor do Programa de Pos-Graduação em Memória Social da Universidade Federal do Estado do Rio de Janeiro, Rio de Janeiro, RJ, Brasil. E-mail: ricosalz@uol.com.br

2 Mestrando do Programa de Pos-Graduação em Memória Social da Universidade Federal do Estado do Rio de Janeiro, Rio de Janeiro, RJ, Brasil Bolsista CAPES. E-mail: felipetlourenco@hotmail.com
} 
Desta maneira, existiria "uma clara distinção entre o conhecimento verdadeiro dos filósofos, que se voltam para a verdade em sua totalidade e universalidade e a simples opinião dos homens comuns, que vivem como se estivessem num sonho" (FRONTEROTTA, 2014, p.38). Estabelece-se aí os dois mundos separados no pensamento de Platão: o mundo das aparências, ligado a todos os enganos provenientes da ordem do sensível e o mundo das Ideias, ligado à ordem da verdade. O mundo das Ideias corresponde, portanto, a outra realidade diferente da realidade sensível e que contém em si a essência das coisas. Nesta perspectiva, a essência é tida como algo imutável e imune a todas as transformações características do mundo das aparências. Este seria uma cópia imperfeita do mundo das Ideias e que, por isso, conduziria constantemente ao erro.

Em suma, a ordem do sensível diz respeito às experiências singulares dos mais diversos indivíduos que se voltam para a realidade sempre em conformidade com suas paixões ou interesses. Por isto, os conhecimentos que os homens comuns produzem não são necessariamente verdadeiros. Já o filósofo seria aquele que, em busca da verdade, ultrapassaria o domínio das aparências, ascendendo ao mundo das Ideias através do pleno uso da razão, tal como é exemplificado na famosa alegoria da caverna. Nela, um dos prisioneiros, ao sair das trevas, vê a luminosidade do dia e, com isso, passa a ver as próprias coisas como elas são e não mais as suas sombras. Há, portanto, uma analogia entre este prisioneiro e o filósofo que, ao caminhar para além das aparências, conseguem ver a luz e contemplar a verdade.

Com efeito, ao longo do desenvolvimento do pensamento filosófico foram vários os autores que apoiaram suas concepções sobre a verdade nestes referenciais platônicos, ou pelo menos, naquilo que os estrutura. No entanto, a partir do século XIX, tais concepções passaram a sofrer duros golpes, o que abriu o devido espaço para que alguns pensadores do século $X X$ trabalhassem dentro de outros paradigmas (CHÂTELET, 1994). Neste contexto, a proposta do presente artigo é analisar como dois destes filósofos - Foucault e Benjamin - entendem o conceito de verdade, destacando os referenciais nos quais se apoiam e examinando 
as devidas consequências de suas concepções para o pensamento contemporâneo ${ }^{3}$.

Trata-se, em primeiro lugar, de demonstrar como, em suas teorias, o conceito de verdade deixa de atrelar-se à ideia de essência. Ou seja, para eles, a verdade não consiste em algo permanente e sempre idêntico a si mesmo. Pelo contrário, ela possui um caráter fundamentalmente histórico e contingencial. Em outros termos, ressaltamos que, de acordo com tais autores, a verdade jamais é una ou universal, mas algo eminentemente relativo, na medida em que depende dos mais diversos fatores contextuais e circunstanciais. Um segundo ponto a ser destacado é a concepção de que a verdade pode consistir em uma produção ou construção e jamais em algo que se encontra desde sempre escondido em algum lugar a ser devidamente descoberto por algum filósofo ou cientista. Por tais fatores, podemos até mesmo depreender ser mais plausível utilizar o termo "verdades" - no plural - se tivermos como referência as obras de Foucault e Benjamin.

Conforme veremos, temos, aqui, uma análise que em muito pode contribuir para o campo de estudos da memória social, principalmente, quando este é caracterizado como um domínio propriamente transdisciplinar (GONDAR, 2016). De acordo com esta acepção, o campo da memória social é visto como que atravessado por uma extensa rede de saberes que se entrecruzam, sem necessariamente visar à síntese como um final desejado. Segundo esta proposta, a verdade jamais pode se constituir como vinculada a uma essência ou à ordem do universal e mesmo como aquilo que se esconde por detrás de quaisquer fenômenos do mundo. O conceito de verdade será por nós valorizado como uma produção de uma extensa rede que engloba fatores científicos, históricos, políticos, sociais e mesmo subjetivos, e jamais como o que se encontra na origem e no princípio de tudo. Vale, por fim, destacar novamente o caráter restrito dessa discussão, na

\footnotetext{
${ }^{3}$ Claro está que aqui temos um enorme salto no tempo, salto este que parte de Platão e chega a dois filósofos do século XX. De fato, o conceito de verdade foi objeto de uma discussão filosófica bastante abrangente ao longo dos séculos, sendo definido das mais diversas formas e sofrendo inúmeras problematizações a depender do filósofo que sobre ele se debruçava. No entanto, uma discussão sobre o conceito de verdade na história da filosofia não é propriamente o objeto de estudo deste artigo, tratando-se nele apenas de contrapor, de um lado, as concepções platônicas e, de outro, as visões benjaminianas e foucaultianas sobre o tema. Uma análise mais detalhada a respeito do conceito de verdade na história da filosofia ultrapassaria os limites deste artigo, ficando esta discussão para outra oportunidade.
} 
medida em que temos como autores centrais apenas Benjamin e Foucault e trabalhamos em suas contraposições aos referenciais platônicos acima descritos.

\section{A PRODUÇÃO DE VERDADES EM FOUCAULT}

Conforme destacamos, em Foucault, o conceito de verdade não se encontra atrelado à ideia de universalidade e muito menos a uma espécie de essência a ser encontrada por detrás das aparências. Aliás, quando Foucault escreve sobre a verdade, ele jamais a conceitua como algo a ser descoberto. Pelo contrário, ela é sempre encarada enquanto uma produção, produção esta que possui como pano de fundo uma microfísica de poderes.

É esta a concepção que pode ser extraída da leitura de alguns de seus principais escritos como "Vigiar e punir" (FOUCAULT, 2008), "Nietzsche, a genealogia e a história" (FOUCAULT, 1979a) e "Verdade e poder" (FOUCAULT, 1979b). Neste último, seu foco é examinar a relação entre os termos presentes no título, visando circunscrever que o poder é fundamentalmente produtor de verdades. Em outros termos, a verdade não se configura como algo que exista para além da trama microfísica de poderes. Pelo contrário, ela é por esta trama minuciosamente arquitetada e regulamentada. Neste sentido, cada sociedade possui seu próprio regime de construção de verdades, sendo a trama de micropoderes ali presente a responsável por legitimar quais discursos são tidos como verdadeiros, bem como por deliberar quem são aqueles aptos por enunciar determinadas verdades:

a verdade não existe fora do poder. Não é [...] a recompensa dos espíritos livres, o filho das longas solidões, o privilégio daqueles que souberam se libertar. A verdade é deste mundo; ela é produzida nele graças a múltiplas coerções e nele produz efeitos regulamentados de poder (FOUCAULT, 1979b, p. 12).

Desta passagem, podemos extrair uma crítica bastante incisiva às concepções platônicas. Com efeito, Foucault declara que o conhecimento verdadeiro não é aquele a ser obtido pelos espíritos libertos do mundo da doxa e que finalmente saíram das trevas da caverna. Tampouco, ela se encontra em outro mundo: a verdade é aqui mesmo produzida e sancionada enquanto tal. É também este mundo que sofre os efeitos de poder promovidos pelas ditas verdades que aqui circulam.

De fato, todas estas concepções possuem como base a ideia de que entre a verdade e o poder as relações são bem complexas: o poder produz verdades e R. Inter. Interdisc. INTERthesis, Florianópolis, v.14, n.1, p.41-59 Jan.-Abr. 2017 
estas exercem um poder crucial sobre a sociedade. Nesta medida, a proposta central de "Vigiar e punir" é demonstrar como se deu o advento da sociedade disciplinar a partir da substituição das técnicas de suplício características do Antigo Regime pelos mais minuciosos dispositivos de disciplinarização dos corpos. Desta forma, a Europa assistiu ao alastramento das mais diversas instituições panopticas família, escola, fábrica, hospício, etc. - por todo o tecido social, instituições estas que visavam à disciplina dos que lá se inseriam, pelos dispositivos de vigilância e normalização e pela aplicação de exames contínuos. Neste modelo de sociedade, faz-se necessário estudar os indivíduos a fim de corrigir aqueles que não conseguiam se adequar às normas, sempre na tentativa de produzir bons cidadãos.

Tal disciplinarização deveria ser necessariamente atrelada à constituição de uma diversidade de saberes sobre os homens, saberes tidos como pretensamente científicos, sendo todos eles devidamente legitimados pelas instituições panopticas. Em outros termos, se a questão era disciplinar os corpos a fim de torná-los úteis, tal artimanha de poder só poderia ser eficaz se atuasse em conjunto com esta série de saberes - as ditas ciências humanas - encarregadas de produzir conhecimentos sobre o homem, conhecimentos estes com funções basicamente normativas, diagnósticas e prognósticas. É, portanto, aí que Foucault (2008) situa epistemologicamente o nascimento das ciências do homem. Pela primeira vez, a Europa sentiu necessidade de promover um saber deste tipo, sendo somente a partir deste momento que o homem passa a fazer questão para a sociedade, constituindo-se enquanto um possível objeto de estudo científico.

Deste modo, Foucault começa a evidenciar as complexas relações entre os domínios do poder e do saber. Por um lado, o poder deve necessariamente produzir saber visando à sua eficácia. Com isto, abandona-se a ingênua concepção de que um saber autêntico só pode nascer quando algumas artimanhas políticas ficam suspensas, artimanhas tais que poderiam contaminar as verdades enunciadas pelo saber em questão. Por outro lado, também não haveria um saber que não constituísse determinadas relações de poder. Ou seja, o saber sempre possui o poder de enunciar verdades sobre seu objeto de estudo, verdades estas que governarão todas as relações humanas existentes nos contextos disciplinares (FOUCAULT, 1979b). 
Vejamos alguns exemplos. Desde o seu advento, a sociedade disciplinar assistiu à multiplicação dos designados internatos por todo o solo europeu, sendo justamente neste contexto que são formulados conceitos de infância e de família tal como hoje conhecemos (ARIĖS, 2012). Com tudo isto em jogo, surge a proposta de educar e disciplinar as crianças, visando com que elas se transformem em bons e produtivos adultos. Para tal, a família deveria, sobretudo, conceder afeto a elas. Às crianças passa a ser também circunscrito um lugar no seio da estrutura familiar, o lugar da pureza e da inocência, sendo os pais encarregados de investir nos filhos em todos os sentidos. As crianças deixam de trabalhar e passam a frequentar tais internatos, por sua vez, encarregados da boa educação e da disciplinarização.

É necessário marcar que tal proposta não poderia ser empreendida sem o necessário apoio em alguns saberes - dentre os quais podemos mencionar a pedagogia - responsáveis, dentre outras coisas, por produzir melhores estratégias para o processo de ensino e aprendizagem, bem como por identificar as crianças que não se adequam ao bom ensino e lançar alguns artifícios que visem suas recuperações. Assim, por um lado, é o poder disciplinar que acaba produzindo uma série de saberes sobre a infância, sendo tais saberes legitimados enquanto detentores do poder de enunciar verdades sobre crianças, adolescentes, famílias e instituições de ensino. De fato, ao longo dos séculos que sucedem ao nascimento da sociedade disciplinar, as instituições de ensino são invadidas por um exército de cientistas encarregados de avaliar as crianças e produzir verdades sobre elas. É justamente ao longo dos séculos disciplinares que surge a conhecida categoria de "criança problema", bem como a ideia de que uma família desestruturada necessariamente acarreta na criação de uma criança indisciplinada, além de tantas outras verdades incessantemente legitimadas pelos saberes científicos.

O mesmo dinamismo pode ser observado nas práticas de internação dos loucos em hospícios para oferecer-lhes tratamento adequado. Neste contexto, o saber psiquiátrico entra em cena enquanto produtor de verdades, verdades estas construídas mediante a observação e classificação dos sintomas de cada indivíduo e que culminam na criação de diagnósticos como esquizofrenia, paranóia, dentre outros. O saber psicológico também se insere neste panorama disciplinar produzindo verdades do tipo "uma boa criação deve necessariamente envolver o carinho dos pais e o convívio com outras crianças" ou "o constante contato dos 
indivíduos com práticas de violência acarreta no surgimento de tendências agressivas". Trata-se, de acordo com a ótica foucaultiana, não de verdades descobertas pelos saberes científicos, mas de verdades por eles próprios produzidas.

Para Foucault, as verdades são, portanto, da ordem da produção. Elas só passam a existir a partir de uma trama política de poderes e, assim, conseguem adentrar por todo o tecido social, governando as relações que ali se fazem. Nesta perspectiva, o que se coloca como principal questão não é se tais enunciados científicos são fundamentalmente coerentes e aceitáveis do ponto de vista formal ou mesmo verificáveis através dos dispositivos experimentais. Em outros termos, não se trata exatamente de saber se tais proposições são verdadeiras ou falsas, importando antes denunciar os mecanismos de poder que elas fazem circular:

\footnotetext{
o problema não é de se fazer a partilha entre o que num discurso releva da cientificidade e da verdade e o que relevaria de outra coisa; mas de ver historicamente como se produzem efeitos de verdade no interior de discursos que não são em si nem verdadeiros nem falsos (FOUCAULT, 1979b, p. 7).
}

Com base nestes pressupostos, Foucault lança, de forma resumida, algumas importantes proposições a respeito do conceito de verdade. A primeira delas é que, em nossa sociedade, a verdade é produzida pelos discursos científicos incessantemente legitimados pelas instituições que nos atravessam. A segunda diz respeito à necessidade que esta mesma sociedade possui de produzir verdades, de modo que elas se encontrem submetidas a incitações tanto de ordem econômica quanto políticas. Por fim, há a evidência de que as verdades são objetos de uma imensa difusão por todo o tecido social e de um consumo exacerbado, de forma que elas circulem sem parar por todos os aparelhos de informação.

É neste sentido que, em Foucault, o poder não é apenas conceituado em termos negativos, como se focalizasse somente sua dimensão repressiva ou censora. Pelo contrário, o poder é fundamentalmente produtivo. Ou seja, ele produz verdades acerca dos indivíduos e da sociedade e tais verdades acabam mesmo por interferir - ou mesmo construir - a realidade. Para ele, a verdade jamais existe fora da articulação entre poder e saber. Os saberes inseridos nas tramas microfísicas de poder, além de criar enunciados pretensamente verdadeiros, tendem a constantemente remetê-los a uma espécie de essência, sendo justamente isto o que deve ser problematizado, já que tal procedimento inevitavelmente conduz à 
naturalização destas verdades. Com isto, a sociedade acaba tomando como naturais algumas verdades que possuem, sobretudo, um caráter histórico e contingencial, sendo frutos das mais diversas artimanhas de poder.

\section{VERDADES E RESSIGNIFICAÇÕES EM BENJAMIN}

Em sua teoria, Benjamin também se distancia da ideia de verdade absoluta, optando por valorizar as mais diversas constelações de verdades e conhecimentos construídos a serem sempre reinterpretados e nunca cristalizados. Com efeito, seu pensamento talvez tenha como principal característica o inacabamento e a abertura, de modo que ele evita - talvez de forma proposital - conclusões permanentes, fechadas ou acabadas. Neste sentido, é impressionante notar o quanto ele busca demonstrar potência e positividade no inacabamento, nas múltiplas possibilidades, na morte, no fim e nas rupturas, evidenciando como uma ressignificação e uma criação podem daí advir.

Por estes motivos, Benjamin se distancia do pensamento platônico, bem como de suas estratégias que buscam convencer o interlocutor de que aquilo que ele escreve não é algo subjetivo, mas sim, um verdadeiro e fiel relato da realidade. Deste modo, Benjamin potencializa as múltiplas possibilidades de releitura de seus textos e a dessacralização de suas narrativas. Entende-se que seus trabalhos:

evocam o sentimento de que não foram acabados, de que o que se lê é um fragmento cindido [...] que [...] torna-o provisório, já que representa aquilo que nunca poderá ser captado como totalidade orgânica, porque (Benjamin o sabe) essa totalidade se perdeu (SARLO, 2013, p. 46).

Para Benjamin, portanto, a verdade não seria obtida através de uma síntese ou conclusão. Pelo contrário, ela se situaria nas próprias dobras e nos detalhes de uma colcha de retalhos infinitos de modo a evidenciar que não há síntese sem conflitos e que uma dita verdade não é homogênea, mas sempre um local de confrontos e contradições.

Assim, ao nos voltarmos para seu pensamento, percebemos que a verdade não se configura como absoluta e nem deve ser cristalizada em uma forma duradoura, sendo passível de sofrer as mais diversas interpretações. De fato, a verdade deve ser constantemente revisitada e repensada, como forma de afastá-la de um status dogmático e eterno. O autor acredita que "quem alguma vez começou 
a abrir o leque da memória não alcança jamais o fim de seus segmentos; porque descobriu que o leque pode desdobrar-se e que a verdade reside em suas dobras" (SARLO, 2013, p. 43). Em outros termos, destaca-se que para quem optou pela estrada não dogmática da busca pela verdade, existe um caminho infinito que se abre a cada busca, a cada pergunta e a cada narrativa. Nesta concepção, a busca pela verdade se faz de maneira interminável e sempre inacabada, já que seus sentidos se cruzam na forma de uma constelação, ocasionando entrelaçamentos, conflitos e rupturas, gerando novos e múltiplos sentidos. Este é um ponto crucial da obra de Benjamin:

nada pode ser terminado por completo, todo trabalho supõe uma construção em abîme, na qual cada dobra remete a outra dobra, e desdobrar as fissuras de um texto ou de uma lembrança conduz ao encontro de novas fissuras; alisar uma imagem, como ele gostava de dizer, é encontrar na nova superfície as linhas da superfície anterior, mas modificadas (SARLO, 2013, p. 43-44).

Benjamin trata destas questões de forma mais específica em três textos: "O narrador" (BENJAMIN, 1936/1987), o Prefácio à "Origem do drama barroco alemão" (BENJAMIN, 1928/1984) e as "Teses sobre o conceito de história" (BENJAMIN, 1940/1987). No primeiro, a discussão tem como pano de fundo o advento da Modernidade, período de mudança de práticas antes consolidadas e de rupturas com o passado. Sua questão é saber como se inserem neste contexto as transmissões de saber, de experiências, de histórias e de verdades. Com isto, enfatiza-se como as múltiplas possibilidades de ressignificações da verdade se colocam na construção de histórias, de narrativas historiográficas e na própria constituição de memórias.

No texto em questão, ele faz algumas considerações sobre a obra de Nikolai Leskov, de maneira a estabelecer diferenças entre a forma de transmissão de saber tradicional - representada na figura deste autor, e que, segundo Benjamin, está em vias de extinção - e as novas formas de transmissão personificadas pelo romance e pela informação. No contexto destas últimas, o saber transmitido dificulta o fornecimento de interpretações variadas àquilo que é escrito ou falado. De modo contrário, no contexto da narrativa, haveria a possibilidade de nos distanciarmos do autor, no sentido de abrirmos possibilidades para as nossas próprias ressignificações sobre o que é narrado. 
Deste modo, ele identifica algo fundamental na narrativa tradicional: a fonte a qual recorrem os narradores é a experiência acumulada ao longo de suas vidas e que passa de pessoa a pessoa, absorvendo vestígios e marcas de cada narrador e, portanto, ressignificando-se incessantemente. Nesta medida, Benjamin compara a narrativa ao processo artesanal de produção. Com isso ele quer enfatizar que, em seu processo de transmissão, a narrativa se molda incessantemente de forma a incorporar vestígios e rastros dos diversos narradores e ouvintes. Por isso, na narrativa, seria incorreto supor a existência de uma verdade única, já que ela é carregada de um caráter inconclusivo que sugere as mais diversas possibilidades de criação, o que contraria as pretensões a conclusões ou reflexões homogêneas. É isto o que aproxima a narrativa tradicional da concepção de história defendida no Prefácio à "Origem do drama barroco alemão" e nas "Teses sobre o conceito de história".

No primeiro - no qual Platão é inclusive mencionado -, a problematização do conceito de verdade tem como pano de fundo a visada crítica que Benjamin faz da ideia de origem, contrapondo-a com a noção de gênese. Nesta perspectiva, enquanto a última se atrela a um passado de forma a englobar o início e o porvir de algo segundo uma lógica progressista, a origem consistiria em uma categoria fundamentalmente histórica.

Assim, ao caracterizar a ideia de origem como histórica, Benjamin (1928/1984) destaca que apesar dela remeter a um passado, fica impossível retornar-se ao dado bruto, ponto de partida de todo um processo que se desenvolveria em uma trama progressista. Segundo esta concepção, as mais variadas tentativas de rememoração, por exemplo, estariam fadadas ao fracasso, tendo que ser necessariamente problematizadas, visto que o dado bruto estaria para sempre perdido. Daí a proposta de denunciar também a incompletude e o inacabamento dos trabalhos de restauração ou reprodução, já que Benjamin não abre espaço, em sua teoria, para qualquer espécie de retorno ao passado tal como fora realmente vivenciado.

De acordo com esta abordagem, podemos depreender que os fenômenos históricos só adquirem efetivamente seus sentidos a posteriori, quando vem a formar uma espécie de traçado com outros fenômenos. Em outros termos, um suposto evento originário sempre "se localiza no fluxo do vir a ser como um torvelinho" 
(BENJAMIN, 1928/1984, p. 68), ou seja, algo como um redemoinho que captura uma série de acontecimentos, misturando-os, e fazendo emergir uma nova configuração.

Portanto, fazer história não seria exatamente acumular fatos ou narrativas na forma de um continuum, mas sim, um trabalho eminentemente construtivo do passado, trabalho este que se opera enquanto uma verdadeira revolução, "um salto de tigre em direção ao passado" (BENJAMIN, 1940/1987, p. 230), que acaba por implodir o continuum dos acontecimentos. Deste modo, seu conceito de história se reporta a outra idéia de temporalidade que não a da causalidade linear entre acontecimentos. Com efeito, história se faz através de um conjunto de saltos e recortes para fora da linha do tempo cronológico.

É neste contexto que pode ser situado o exemplo relativamente irônico apresentado nas "Teses sobre o conceito de história" sobre a significação que a Roma Antiga passa a adquirir a partir da Revolução Francesa. De fato, Robespierre não se cansou de mencionar a Roma Antiga com o intuito revolucionário de apropria-se de um passado republicano na história da humanidade. Esta atitude serve como ilustração para o salto de tigre acima mencionado, para mais além da linearidade cronológica ou progressista entre estes dois eventos tão distantes no tempo. Em virtude desta apropriação, passa a se desenhar um traçado entre a Roma Antiga e a Revolução Francesa e, com isto, ambos os eventos passam a adquirir um novo sentido. Ou seja, com este traçado, não apenas o passado é transformado, mas também o próprio presente (BENJAMIN, 1940/1987).

Portanto, para Benjamin, a verdade que se vincula à construção histórica é sempre algo dinâmico e que se dá a partir do tempo presente, de forma que a história é concebida como "anti-linear, baseada na descontinuidade, na ruptura, na catástrofe, e não na sucessão simples ou dialética de fatos ou etapas" (ROUANET, 1990, p. 20). É neste sentido que o Prefácio à "Origem do drama barroco alemão" e suas "Teses sobre o conceito de história" também estão serviço da problematização da ideia de uma verdade absoluta. Abre-se, também aqui, o devido espaço para a possibilidade de se fornecer múltiplas interpretações para um mesmo fato. Isso gera a necessidade de constantes revisitações ao que é tido como verdade.

Com efeito, para o historiador, mais importante do que apresentar conclusões, seria colocar questões em evidência, o que acaba gerando uma reflexão da parte de seus interlocutores. Isto deixará o caminho livre para as múltiplas ressignificações 
que daí vão advir, sendo nesta constelação de possibilidades que Benjamin busca a redenção da história e da verdade. Salvar a história significa entender as múltiplas possibilidades de interpretação contidas em um fato, significa combater cristalizações homogêneas de verdades absolutas:

O passado traz consigo um índice misterioso, que o impele à redenção. Pois não somos tocados por um sopro do ar que foi respirado antes? Não existem, nas vozes que escutamos, ecos de vozes que emudeceram? Não tem as mulheres que cortejam as irmãs que elas não chegaram a conhecer? Se assim é, existe um encontro secreto, marcado entre gerações precedentes a nossa. Alguém na terra está á nossa espera. Nesse caso, como a cada geração, foi-nos concedida uma frágil força messiânica para qual o passado dirige um apelo. Esse apelo não pode ser rejeitado impunemente (BENJAMIN, 1940/1987, p. 223).

Conforme estamos destacando, Benjamin combate o trabalho de construção das verdades absolutas que seriam utilizadas como instrumentos de perpetuação de memórias em prol da manutenção de determinados status ou classes. Para ele, o processo de construção histórica não pode ter por fim a construção de verdades indiscutíveis e imutáveis. Por entender que existem múltiplas possibilidades na forma como se constituir verdades, ele acaba concebendo a história como um local de conflitos, como um instrumento de salvação para aquelas verdades cristalizadas e como uma fonte de criação que possibilite, através da contradição, a heterogenia dentro de memórias antes eternizadas e nunca revisitadas. Nesta possibilidade aventada por Benjamin, o conhecimento historiográfico não deve ser resgatado e eternizado de forma dogmática, mas sim, constantemente reconstruído.

Assim, ele afirma que "articular historicamente o passado não significa conhecê-lo tal como ele propriamente foi". Significa apoderar-se de uma reminiscência tal como ela relampeja no momento de perigo" (BENJAMIN, 1940/1987, p. 224). Isso significa dizer, que na concepção de Benjamin o tempo histórico, ou o tempo da construção do conhecimento historiográfico, foge a homogeneidade e a linearidade do tempo do relógio de pulso. Enquanto o tempo cronológico é homogêneo e linear, o tempo histórico é heterogêneo, constituído em forma de redes e carregados de momentos atuais. Com isto Benjamin potencializa e aplica uma concepção qualitativa à descontinuidade do tempo histórico, o que leva a uma interrupção revolucionária da continuidade historiográfica.

Neste sentido, o conhecimento historiográfico torna-se imprevisível e aberto a consideração de novas possibilidades. Futuro, presente e passado entrelaçam-se 
nessas redes de possibilidades e a narrativa histórica que triunfou pelos séculos deixa de ser a única possível. Segundo esta ótica, o presente e o futuro encontramse em posição de abrir narrativas antes cristalizadas e, portanto, reconstruir e ressignificar verdades e/ou passados consolidados. Desta maneira, o passado passa a ser compreendido como algo que não é encerrado em si próprio, mas como algo que só possui sentido em um contexto específico.

É neste ponto também que podemos perceber as analogias entre os conceitos de história e de narrativa em sua obra, na medida em que ambos estão ligados à relativização do conceito de verdade. Isso significa que tanto a narrativa como a produção de um saber histórico consistem na conjunção de um passado individual com um passado coletivo inter-relacionados na transmissão de uma memória de caráter inconclusivo e inacabado, o que abre espaço para o trabalho do narrador, do pesquisador, do historiador e de seus ouvintes ou leitores permearem suas ressignificações de diferentes vestígios, marcas e interpretações e construírem a mais variada gama de verdades.

Desta forma, a memória do narrador ou o saber construído por um pesquisador são, ou deveriam ser, objetos de constantes revisitações sob pena de se tornarem fechados em si e permeados de verdades absolutas e para sempre cristalizadas. Nesse sentido, a ideia de morte adquire, no pensamento de Benjamin, a potencialidade de impelir para a criação do novo. Para o filósofo, tanto na construção de narrativas como na construção de um saber histórico, a morte entendida tanto em um sentido material como em um sentido metafórico e poético se apresenta como uma chance de reconstruir e de reformular tradições. Neste sentido, a morte ou a ruptura não representam apenas o fim, mas também o início. Aqui, a morte representa criação, representa ressignificação, ela é "a obra da salvação do Ursprung é, portanto, ao mesmo tempo e inseparavelmente, obra de destituição e de restituição, de dispersão e de reunião, de destruição e de construção" (GAGNEBIN, 1994, p. 20). Esse caráter de constantes revisitações e ressignificações, da construção a partir da destruição, atribuídas por Benjamin as narrativas tradicionais e a construção de conhecimentos é que tornam a verdade algo a ser construído permanentemente dentro de uma constelação de possibilidades que tendem para o infinito. 


\section{VERDADES E MEMÓRIA SOCIAL}

Nossa argumentação propôs apresentar duas formas de conceituar a verdade distintas do entendimento platônico que, dentre outras argumentações, estabelecia que o verdadeiro discurso é aquele que apreende as coisas como elas realmente são. No entanto, se partirmos deste pressuposto, um sério problema é levantado, pois a existência de uma verdade absoluta e irrefutável deve necessariamente admitir uma realidade eminentemente estática. Trata-se, em outros termos, de questionar:

se a realidade é um devir constante e ininterrupto, como admitir uma verdade estável? Se tudo muda, mudam não só as coisas, como também o nosso olhar. Como pretender uma adequação constante entre as palavras e a coisas? (GARCIA-ROZA, 2005, p. 50).

Nesta perspectiva, nossa crítica ao modelo platônico do conceito de verdade entende que esta não é eterna e homogênea, assim como também não são as relações sociais por ela expressas. A verdade é um produto histórico e transitório, sendo que qualquer conhecimento a ser produzido, o deve ser com base neste pressuposto. Por este viés, um conhecimento da realidade precisa dar conta da historicidade e da complexidade presente nas relações e também das mediações e contradições que fazem com que a realidade não seja estática e eterna, mas sim, móvel e efêmera. Deste modo, a verdade deixa de se ligar à essência das coisas e passa a ser vista através de suas características contingenciais e históricas. Ela deixa de ser vinculada a uma forma de compreensão linear e universal e passa a ser entendida à maneira de uma constelação de construções históricas e discursivas.

Todas estas considerações podem ser devidamente extraídas da abordagem foucaultiana. Conforme vimos, em sua teoria, a verdade é sempre tida como uma produção ou construção. Ela não consiste exatamente naquilo que está escondido ou encoberto, mas naquilo que se mostra a todo instante, sendo minuciosamente arquitetada pela trama de poderes e saberes. Cada sociedade possui suas próprias verdades e estas, por sua vez, não cessam de legitimar, de modo incisivo, todas as instituições que ali se fazem presentes.

Também para Benjamin, a verdade é uma construção histórica. Em sua argumentação, o pesquisador deve ser capaz de reinterpretar os fatos, experiências, materiais e objetos pesquisados, de forma a lançar uma nova luz sobre eles e 
permeá-los de marcas e vestígios que possibilitem a ressignificação de uma verdade outrora consolidada. Benjamin traz à tona a existência de uma nova forma de construção de verdades, nova forma na qual o passado é salvo no presente e o lembrar não se configura como mera descrição do passado como ele realmente foi, mas uma construção, aonde memória, saber e verdade são múltiplos, processuais, históricos e mutáveis.

Por isso, ainda em referência a Benjamin, seria mais prudente utilizar o termo "verdades", já que, para ele, a verdade não é una, existindo múltiplos caminhos, infinitas possibilidades e buscas intermináveis. As construções de verdades, das memórias e do passada jamais podem se dar de forma completa, devendo sempre ser revisitadas. Conforme exposto anteriormente, as verdades se encontram nas dobras dos leques e suas formas apontam para o conflito, a contradição e o infinito. Salvar a história significa entender as múltiplas possibilidades de interpretações contidas em um fato, significa combater cristalizações homogêneas e verdades absolutas.

Com efeito, a presente análise sobre o conceito de verdade em Foucault e Benjamin é de suma relevância para o campo de pesquisas em memória social. Sabe-se que tal campo constituiu-se enquanto um domínio sistematizado de saber a partir dos estudos de Halbwachs (2003) sobre a existência de uma memória coletiva, para além da já conhecida e estudada memória individual. A partir daí, a memória social passou a ser circunscrita a partir de uma pluralidade imensa de abordagens, de forma que sempre atravessou e foi atravessada pelos mais diversos campos de saber. Com base nesta configuração, podemos dizer que tal domínio jamais pode ser encarado como algo estático. Pelo contrário, o conceito de memória social é algo que se move de forma constante e que, portanto, abrange uma multiplicidade imensa de definições, consistindo em um território eminentemente aberto e, sobretudo, acolhedor do múltiplo.

Assim, segundo Gondar (2016), o campo da memória social se configura como transdisciplinar, no sentido que seu objeto de estudo passa a ser criado e estudado sempre de maneira transversal, atravessando os limites rigorosos existentes entre as mais diversas disciplinas. Com isto, a memória social não pertence a um domínio específico de saber e nenhum dos diversos saberes tradicionais teria a possibilidade de cunhar o seu conceito. Ademais, a autora 
estabelece que o conceito de memória social é propriamente ético e político. Ou seja, qualquer acepção escolhida para abordá-lo necessariamente possui algum nível de parcialidade, jamais configurando-se como neutra. Ainda, a memória social merece ser encarada como uma produção processual, ou seja, uma construção humana que varia conforme o tempo na qual está inscrita. Ela não consistiria exatamente em uma reconstituição do passado, mas em uma reconstrução feita a partir de nós mesmos no tempo em que vivemos.

Desta forma, a memória social é algo que está em ininterrupta construção e reconstrução, sempre relacionada a um jogo incessante de forças e poderes, o que conduziria a uma heterogeneidade bastante rica de conceituações e abordagens. É justamente neste sentido que nossa análise sobre o conceito de verdade pode contribuir para este campo, já que ambos autores por nós examinados combatem a ideia de absoluto ou de essência e valorizam o que há de transitório no domínio do saber, caracterizando a verdade como uma produção eminentemente humana e como sempre finita em relação ao tempo. Sendo a verdade situada dentro de uma trama microfísica de poderes - conforme Foucault - ou conceituada enquanto carregada das marcas e vestígios daqueles que a pesquisam - conforme Benjamin -, ela sempre comportará uma parcialidade, o que the confere um caráter propriamente ético e uma dimensão eminentemente política. Por tais fatores, o campo de pesquisa em memória social deve ser sempre relativizado, debatido e incessantemente revisitado.

Por fim, devemos deixar claro que mediante tal estudo, não defendemos a ideia de uma relativização absoluta da verdade, o que poderia conduzir a sérios problemas no que diz respeito à busca, transmissão ou construção de conhecimentos. Defendemos que o saber se constrói através do confronto e da transmissão de experiências mas, ao contrário do que Platão entendia, o resultado deste processo não deve se alocar na condição de uma verdade absoluta. Trata-se, antes, de lançar uma série de questionamentos que apontam para a necessidade de se empreender um trabalho de pesquisa tendo por base outros parâmetros diferentes dos tradicionais. A estrada a ser caminhada na busca pela construção do saber é a estrada do critério, da metodologia e do embasamento teórico científico, de maneira que o pesquisador obtenha logro na busca pela dessacralização de verdades estáticas, sem cair no engano da relativização absoluta do saber científico. 


\title{
THE TRUTHS IN FOUCAULT AND BENJAMIN: A CONTRIBUTION TO THE FIELD OF SOCIAL MEMORY
}

\begin{abstract}
:
The proposal of this article is to analyze how the concept of truth is conceptualized in Foucault and Benjamin, highlighting the criticism that both make reference to the Platonics. We highlight that in their theories, the concept of truth stops to associate of the idea of essence, passing to acquire a historical and contingently character. Moreover, we see that the truth is designed as a production and never as something that is hidden from the beginning and must be appropriately discovered. In Foucault, we focus in several articulations that the concept of truth has with the domains of power and knowledge. In Benjamin, we emphasize how much the author appreciates the multiple meanings that an event may suffer from time to time. Therefore, we examined how far Benjamin is from the absolute truth idea, opting to value the various constellations of truths and knowledge built to be always reinterpreted and never crystallized. Finally, we analyze how our study can contribute to social memory research fields because it can be characterized as a transdisciplinary field that sees its object of study as something procedural.
\end{abstract}

Keywords: Truth. Foucault. Benjamin. Philosophy. Social Memory.

\section{LAS VERDADES EN FOUCAULT Y BENJAMIN: UNA CONTRIBUCIÓN AL CAMPO DE LA MEMORIA SOCIAL}

\section{Resumen:}

El propósito de este artículo es analizar cómo lo concepto de verdad es diseñado en el pensamiento de Foucault y Benjamin, destacando la crítica que ambos hacen la referencia platónica. Destacamos que en sus teorías, el concepto de verdad deja de vincularse a la idea de esencia, va a adquirir un carácter histórico y contingente. Por otra parte, vemos que la verdad se concibe como una producción y nunca como algo que está oculto desde el principio y debe ser descubierto correctamente. En Foucault, nos centramos en las más variadas articulaciones que el concepto de verdad tiene con los campos de poder y saber. Ya de Benjamin destacamos lo mucho que el autor valora las múltiples significaciones que un evento pueda sufrir con el paso del tiempo. Por lo tanto, examinamos cómo Benjamin se distancia de la idea de verdad absoluta, optando por valorar las distintas constelaciones de verdades y conocimientos construido para ser reinterpretados siempre y nunca cristalizados. Por último, se analiza la forma en que nuestro estudio puede contribuir con el campo de investigación en memoria social, en la medida en que esto puede ser caracterizado como un campo transdisciplinario, que entiende su objeto de estudio como algo procedimental.

Palabras clave: Verdad. Foucault. Benjamin. Filosofía. Memoria Social. 


\section{REFERÊNCIAS}

ARAÚJO, C. Verdade e espetáculo: Platão e a questão do ser. 1. ed. Rio de Janeiro: 7 Letras, 2014.

ARIĖS, P. História social da criança e da família. 2. ed. Rio de Janeiro: LTC, 2012.

BENJAMIN, W. Origem do drama barroco alemão. 1. ed. São Paulo: Brasiliense, 1984. (Original publicado em 1928).

. O Narrador. In: BENJAMIN, W. Obras escolhidas I: magia e técnica, arte e política. $3^{a}$ Ed. São Paulo: Brasiliense, 1987. p. 197-221. (original publicado em 1936).

Sobre o conceito de história. In: BENJAMIN, W. Obras escolhidas I: magia e técnica, arte e política. $3^{a}$ Ed. São Paulo: Brasiliense, 1987. p. 222-232. (original publicado em 1940).

CHÂTELET, F. Uma história da razão: entrevistas como Émile Noel. 1. ed. Rio de Janeiro: Jorge Zahar Ed., 1994.

FOUCAULT, M. Nietzsche, a genealogia e a história. In: FOUCAULT, M. Microfísica do poder. 1. ed. Rio de Janeiro: Edições Graal, 1979a. p. 15-37.

FOUCAULT, M. Verdade e poder. In: FOUCAULT, M. Microfísica do poder. 1. ed. Rio de Janeiro: Edições Graal, 1979b. p. 1-14.

FOUCAULT, M. Vigiar e punir. 35. ed. Petrópolis: Vozes, 2008.

FRONTEROTTA, F. Verdade e espetáculo: Platão e a questão do ser. 1. ed. Rio de Janeiro: 7 Letras, 2014.

GAGNEBIN, J. M. História e narração em Walter Benjamin. 1. ed. São Paulo: Editora Perspectiva, 1994.

GARCIA-ROZA, L. A. Palavra e a verdade na filosofia antiga e na psicanálise. 5 . ed. Rio de Janeiro: Jorge Zahar Ed., 2005. 
GONDAR, J. Cinco proposições sobre memória social. Morpheus: revista de estudos interdisciplinares em memória social, Rio de Janeiro, v. 9, n. 15, p. 19-40, 2016.

HALBWACHS, M. A Memória coletiva. 1. ed. São Paulo: Centauro, 2003.

PLATÃO. A República. 1. ed. São Paulo: Nova Cultural, 1997.

ROUANET, S. Édipo e o anjo: itinerários freudianos em Walter Benjamin. 1. ed. Rio de Janeiro: Editora Tempos Brasileiros, 1990.

SARLO, B. Sete ensaios sobre Walter Benjamin e um lampejo. 1. ed. Rio de Janeiro: Editora UFRJ, 2013.

Artigo:

Recebido em 19 de Maio de 2016.

Aceito em 03 de Novembro de 2016. 